\title{
THE USE OF ELECTROENCEPHALOGRAPHIC MONITORING DURING CAROTID ENDARTERECTOMY, AS AN INDICATOR FOR THE APPLICATION OF A TEMPORARY BY-PASS
}

\author{
B. M. Marshall, M.D., F.R.C.P.(C), AND W. M. Lougheed, M.D., F.R.C.S.(C)
}

DuRING the surgical correction of carotid artery stenosis, the carotid artery may be occluded for periods of up to 30 minutes. It is desirable that this occlusion have a minimal effect upon the patient and that the surgeon have some means of evaluating the effect of the resultant decrease in total cerebral blood flow. The anaesthetic technique for the surgical approach to the correction of carotid stenosis must, therefore, fulfil two criteria. First, cerebral blood flow must be augmented to the optimum extent. Secondly, means must be available to detect any inadequacy of cerebral blood flow or cerebral oxygenation.

During the past fifteen years, there has been a considerable amount of work directed toward perfecting the optimum patient selection and the optimum in surgical ${ }^{1,2}$ and anaesthetic techniques, ${ }^{3-6}$ as well as establishing adequate monitoring systems..$^{7-9}$ Adjuvants to therapy have included general anaesthesia, ${ }^{6}$ moderate hypothermia, ${ }^{1}$ induced hypercarbia, ${ }^{5}$ and induced hypertension. More recently, internal by-pass shunts have been used as an aid to maintain optimum cerebral blood flow. The method evolved in this unit attempts to make use of the best parts of the various techniques without unduly complicating the procedure.

\section{METHOD}

Light general anaesthesia, usually with halothane in 50 per cent nitrous oxide and oxygen, is presently used unless another method is specifically indicated. The halothane is frequently supplemented or replaced by neuroleptanalgesic mixture of dehydrobenzperidol and fentanyl citrate.

Moderate hypothermia, employing surface cooling to $30^{\circ} \mathrm{C},{ }^{10}$ is added to the technique in cases in which there is not total occlusion of the involved vessel. The added protection is believed to far outweigh the added inconvenience of carrying out the technique. Although cardiovascular problems do arise, there have been no fatalities attributed to the use of hypothermia in these patients, and there is a low incidence of temporary morbidity.

Induced hypertension and induced hypercarbia are also used in many cases. The experimental basis justifying the use of these latter techniques indicates that a varying degree of benefit is derived.

The use of a local by-pass shunt is now held in reserve for those cases in which the monitoring technique indicates a need to augment the cerebral blood flow when tested by a trial clamp-off. This stand is taken because of two factors. The

\footnotetext{
- Departments of Anaesthesia and Surgery (Neurosurgery), University of Toronto, and the Divisions of Anaesthesia and Neurosurgery, Toronto General Hospital.
} 
altered blood coagulation resulting from the heparinization necessary when a shunt is employed has appeared on occasion to result in troublesome increased bleeding from the arterial suture line. Secondly, some patients in whom a shunt was used have had a temporary postoperative focal paresis. This complication resembled that which would result from a small embolus. It is surmized that an embolus might be formed during the placement of the shunt, or arise from the end of the shunt during the by-pass procedure.

Electroencephalographic changes indicating a decrease in cerebral function occurring during a temporary arterial clamp-off ${ }^{7}$ are used as an indication for the placement of a temporary by-pass. Needle electrodes are placed in the scalp in the frontal, coronal, and occipital areas, $2 \mathrm{~cm}$ from the mid-line. The EEG tracing is recorded during the initial approach as well as during the clamp-off to establish an accurate reference tracing. The anaesthetic technique employed is such that an EEG tracing of 8-10 cycles per second with an amplitude of 10-40 microvolts is usually recorded.

In the majority of cases, carotid occlusion results in no change in the EEG pattern. In these cases we assume that cerebral oxygenation has not been affected to any significant degree. In some cases, however, a distinct change in the pattern occurs a short time after the clamp-off occurs. In these cases the carotid artery is released, and a by-pass is inserted after the EEG tracing has returned to the previous pattern.

The following case history illustrates the method employed. The patient, a 62-year-old obese female, was admitted with a three-year history of multiple transient ischaemic attacks. She had a fifteen-year well-documented history of arteriosclerotic cardiovascular disease with angina, hypertension, and electrocardiographic evidence of myocardial damage with ventricular hypertrophy. The patient had been taking anti-hypertensive medication for five years, including reserpine and pentolinium. Carotid arteriography showed a severe stenosis of the left internal carotid artery and a mild stenosis on the right side.

In hospital, attempts to produce a significant change in prothrombin time failed. The anti-hypertensive medication was discontinued for seven days prior to operation and the patient placed on a regimen of bed rest and mild sedation. Blood pressure readings during this period ranged from $140 / 100$ to $170 / 110$. During this time the patient continued to have transient ischaemic attacks with weakness, numbness, and/or partial aphasia. These attacks varied in duration from minutes to hours. There was no loss of consciousness during this period.

In spite of the problems of cardiovascular disease and obesity, the anaesthetic course was uneventful, and the patient was cooled to a temperature of $30^{\circ} \mathrm{C}$ oesophageal. Occlusion of the common carotid artery resulted in an almost immediate change in the EEG tracing. A pattern of large $4 \mathrm{cps}$ waves transiently appeared, followed by a progressive decrease in amplitude and frequency of the wave pattern, as shown in Figure 1. This change persisted until shortly after the carotid was re-opened, after being occluded for two minutes. The carotid circulation was allowed to remain open for ten minutes. The patient was given heparin, $100 \mathrm{units} / \mathrm{kg}$, and then an internal carotid arterial by-pass was inserted. The operation was completed and the shunt removed. Circulation was occluded 
1 Sec.

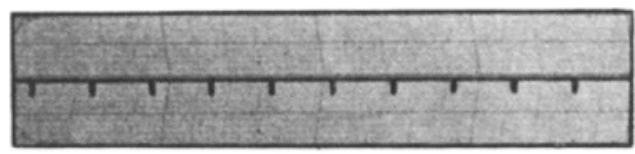

$20 \mathrm{Sec}$.

Before Occlusion

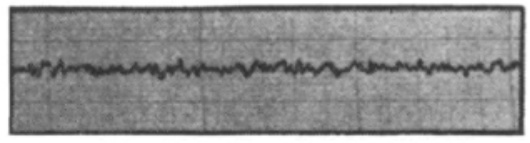

$60 \mathrm{Sec}$.

After Occlusion

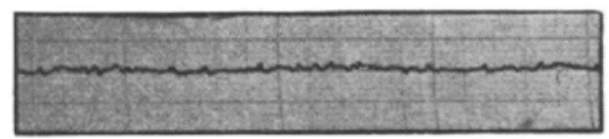

$5 \mathrm{Min}$.

\section{After Reopening}

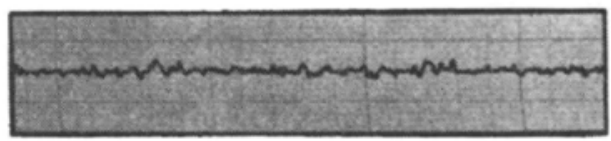

FIgURE 1. EEg tracing before, during, and after clamp-off.

for periods of 2,2, and 4 minutes. During each period of clamp-off the EEG tracing changed as described above, and returned to the "normal" state each time after re-establishment of circulation. The operation was completed uneventfully. The patient awoke without neurological deficit and had an uncomplicated postoperative recovery.

\section{Discussion}

The surgical approach in this hospital to the problem of internal carotid artery occlusion and stenosis is outlined in the article by Lougheed et al. ${ }^{1}$ The selection, investigation, operative preparation, and operative technique have undergone little change from the outline given in that report. This study is based upon the experience gained from fifty consecutive patients operated upon from June 1966 to September 1968.

The use of continuous electroencephalographic monitoring during carotid artery endarterectomy is described and discussed fully in the report of Harris et al. ${ }^{7}$ Their procedures, however, have been done under regional anaesthesia. Wells et al., ${ }^{6}$ however, concluded that general anaesthesia resulted in an increased tolerance to cerebral ischaemia during temporary carotid occlusion. This group also concluded that the EEG was a valuable monitoring guide. Harris et al. ${ }^{7}$ refer to the four methods currently employed to maintain, or hopefully to increase, collateral cerebral flow during temporary occlusion, namely hypercarbia, hypertension, general anaesthesia, and hypothermia. We have concluded that it is 
quite practical to use all of these adjuncts safely, while still employing the EEG as an effective indication of compromised cerebral blood flow. Using this technique, we have been able to select those patients in whom it has been advisable to employ a temporary by-pass.

Some temporary cardiovascular complications occurred during the operations which will be described and discussed in a subsequent publication. Of the 50 procedures performed, 45 were carried out without significant change in cardiac action. Five patients exhibited a moderate to marked arrhythmia with significant fall in blood pressure. These arrhythmias were corrected with appropriate therapy. One patient developed auricular fibrillation which persisted until the end of the procedure. One patient developed a ventricular tachycardia with frequent ectopic ventricular beats which responded to therapy with lidocaine. In no instance was the procedure halted because of cardiovascular problems. In no patient was there a persistent postoperative cardiovascular problem.

\section{Summary and Conclusions}

A continuous EEG monitor was used as a means of indicating the adequacy of cerebral blood flow during a trial clamp-off period in patients undergoing carotid thromboendarterectomy. If the EEG indicated a decrease in cerebral function, in spite of the employment of general anaesthesia, moderate hypothermia, induced hypertension and induced hypercarbia, then a temporary by-pass shunt was employed. The management of a typical case is described.

\section{RÉSUMÉ}

Un moniteur enregistrait continuellement l'EEg chez des malades qui subissaient une thrombo-endartériectomie carotidienne afin d'indiquer la qualité du courant sanguin cérébral durant une période de tentative de clampage. Si l'EGG montrait une diminution de la fonction cérébrale, en dépit de l'anesthésie générale, une hypothermie modérée, un début d'hypertension et d'hypercarbie, alors on pratiquait une dérivation temporaire. On décrit le mode de traitement d'un cas problème typique.

\section{ACKNOWLEDGMENTS}

The authors wish to thank Dr. T. P. Morley and Dr. R. R. Tasker of the Department of Neurosurgery for permission to add their cases to this report.

\section{REFERENCES}

1. Lougheed, W. M., Elgie, R. G., \& Barnett, H. J. M. The Results of Surgical Management of Extracranial Internal Carotid Ártery Occlusion and Stenosis. C.M.A.J. 95: 1279 (1966).

2. Whinsant, J. P.; Siekert, R. G.; Bernaty, P. E.; \& Ellis, F. H. JR. Results of Surgical Treatment of Incipient Stroke. Circulation. 27: 1028 (1963).

3. Jenknns, L. C.; Enceldnecht, E. R.; \& Chunc, W. B. Anaesthetic Considerations for Carotid Thrombo-Endarterectomy. Canad. Anaesth. Soc. J. 14: 309 (1967). 
MARSHALL \& LOUGHEED: ECG MONITORING DURING CAROTI ENDARTERECTOMY 335

4. Marshali, M. Anaesthesia for Carotid Endarterectomy Using Local Brain Perfusion and Cooling. Anaesthesia. 20: 207 (1965).

5. Hormi, J.; Humphries, A. W.; Younc, J. L.; Bevin, E. G.; \& Smart, J. F. Hypercarbic Anesthesia in Cerebrovascular Surgery. Surgery. 59: 57 (1966).

6. Wells, B. A.; Keats, A. S.; \& Cooley, D. A. Increased Tolerance to Cerebral Ischaemia Produced by General Anesthesia during Temporary Carotid Occlusion. Surgery. 54: 216 (1963).

7. Harris, E. J.; Brown, W. H.; Pavy, R. H.; Andehson, W. W.; \& Stone, D. W. Continuous Electroencephalographic Monitoring during Carotid Artery Endarterectomy. Surgery. 62: 441 (1967).

8. Viancos, J. G.; Sickzer, P. H.; Keats, A. S.; \& De Bakey, M. E. Internal Jugular Venous Oxygen Tension as an Index of Cerebral Blood Flow during Carotid Endarterectomy. Circulation. 34: 875 (1966).

9. Claus, R. H.; Hass, W. K.; \& Ransohoff, J. Simplified Method for Monitoring Adequacy of Brain Oxygenation during Carotid-Artery Surgery. New England J. Med. 273: 1127 (1965).

10. Lougheed, W. M. Hypothermia and the Effects of Cold. Brit. Med. Bull. 17: 61 (1961). 